Research Article

\title{
Drug utilization pattern in OPD of government dental college and hospital, Aurangabad
}

\author{
M. D. Kulkarni*, M. S. Baig, Samra A. Hussaini, S. M. Doifode
}

Department of Pharmacology, Govt. Medical College, Aurangabad (MS) 431001, India

Received: 7 December 2012

Accepted: 30 December 2012

*Correspondence to:

Dr. M. D. Kulkarni,

Email: mkulkarni48@gmail.com

\begin{abstract}
Background: To study drug prescription pattern in dental OPD of Government Dental College and Hospital.

Methods: 100 prescriptions were screened \& analyzed as per the study parameters from OPD of Government Dental College \& Hospital, Aurangabad. Groups of drugs commonly prescribed, like antibiotic, analgesics $\&$ others prescription were recorded.

Results: Most common groups of drugs prescribed by dental surgeons were NSAIDs, antimicrobials, antiseptics and multivitamins. NSAIDs- 86\%; Antimicrobials- 85\%; Antiseptics- $8.6 \%$; Multivitamins- $12.3 \%$. The average number of drugs prescribed per patient was 3 and the average number of antimicrobial prescribed per patient was 1 .

Conclusions: For rational prescribing of drugs there is a need of massawareness amongst dental surgeons about the good prescribing by following 6 steps of WHO program on rational use of drugs.
\end{abstract}

Keywords: OPD, Dental, Prescription analysis

\section{INTRODUCTION}

The World Health Organization (WHO) addressed drug utilization as the marketing, distribution, prescription and use of drugs in a society, considering its consequences, either medical, social, and economic. ${ }^{1}$

Drug utilization studies may evaluate drug use at a population level, according to age, sex, social class, morbidity, among other characteristics. These studies are useful to provide denominators to calculate rates of reported adverse drug reactions, to monitor utilization of drugs from therapeutic categories where particular problems can be anticipated. Drug utilization data may be used to produce crude estimates of disease prevalence also. $^{2}$

Drug utilization studies aim to evaluate factors related to the prescribing, dispensing, administering and taking of medication, and its associated events (either beneficial or adverse). Since the early 1960's the interest in Drug Utilization Studies has been increasing, first with marketonly purposes, then for evaluating the quality of medical prescription and comparing patterns of use of specific drugs. The increasing importance of drug utilization studies as a valuable investigation resource in pharmacoepidemiology has been bridging it with other health related areas, such as public health, pharmacovigilance, pharmacoeconomics, ecopharmacovigilance or pharmacogenetics. ${ }^{2}$

Although, a number of studies have been undertaken to study the drug prescribing pattern of physicians, but the data is scarce on the prescribing habits of dental practitioners. $^{3}$

Common problems in dental out patients department are carries, toothache, tooth abscess, gingivitis, tooth extraction. The aim of the present study was to evaluate the drug utilization practices and pattern in Govt. Dental College \& Hospital, Aurangabad (MS) which is the only Govt. dental care hospital for Marathwada region covering eight districts (Jalna, Aurangabad, Parbhani, Hingoli, Nanded, Latur, Osmanabad and Beed). Marathwada region accounts for $16.84 \%$ of the Maharashtra state's population and is home to nearly $30 \%$ of the state's Below Poverty Line families.

\section{METHODS}

Study design

A prospective randomized observational study. 


\section{Study population}

After prior permission from the Head of the institute, all the patients attending the outpatient department of Govt. Dental College and Hospital, Aurangabad for a span of three months were selected. Accordingly a sample of $n=100$ prescriptions of either sex were randomly selected for prescription pattern analysis.

\section{Procedure}

Collected prescriptions were subjected to detail analysis. The drugs prescriptions as regards to antibiotics, analgesics were primarily noted secondarily other drugs prescribed were also noted. Analysis was done for pattern of prescription, group of drugs commonly prescribed, percentage drugs prescribed per prescription. ${ }^{4}$

\section{RESULTS}

Data of $n=100$ patients was analysed as per the study parameters. Most common group of drugs prescribed by dental surgeons were Analgesics (86\%), followed by Antimicrobials (85\%), Multivitamins (12.3\%), Antacids (9.8\%), and Antiseptics (8.6\%).

The average number of drugs prescribed per patient was three; the average number of antimicrobials was one.

Trend was seen that trade names of drugs were used maximally. Common brand names which were used are Capsule Tressmox (Amoxycillin+Cloxacillin), Capsule LMX (Amoxycillin+Lactobacillus), Capsule Ocimix (Ciprifloxacin+Ornidazole), Tablet Citibid (Ciprofloxacin+Tinidazole), Tablet Duoflam (Ibuprofen+Paracetamol in FDC), Tablet Trioflam (Ibuprofen+Paracetamol+Serratiopeptidase), Tablet Combiflam (Ibuprofen+Paracetamol in FDC), Tablet Diclomol (Diclofenac+Paracetamol in FDC), Tablet Aciloc (Ranitidine) and Hexidine (Chlorhexidine) mouth wash.

\section{DISCUSSION}

The prescription trends in patients attending dental outpatient department were studied. The analysis was done for WHO basic drug use guideline, number of drugs prescribed by generic names, number of drugs from essentials medicines list. ${ }^{5}$

The most common groups of drugs prescribed by dental surgeons were antimicrobials, analgesics, antacids, multivitamins, antiseptics. Majority of the prescriptions were according to trade names. The drugs from essential medicine list were commonly prescribed which shows that there is good awareness amongst dental surgeons about essential drugs. ${ }^{5}$

Also it was found that use of antacids or $\mathrm{H} 2$ receptor blockers along with analgesics was not a routine practice which again highlights rationale use of drugs existing in the hospital, but depending upon of history of acid peptic disease it was added.

\section{CONCLUSION}

The prescriptions studied at Govt. Dental College \& Hospital were according to the standard norms of WHO prescriptions \& from the list of essential drug list. For rational prescribing there is need of mass awareness amongst dental surgeons about good prescribing following 6 steps of WHO programme on rational use of drugs. Every Institution must have its own Drugs \& Therapeutics committee as per suggested by WHO so that patients will be benefited by decreasing economical burden, decreasing adverse drug reaction and by increasing therapeutic effect. ${ }^{5,6}$

\section{Funding: No funding sources \\ Competing interests: None declared \\ Ethical approval: Not required}

\section{REFERENCES}

1. WHO Expert Committee. The Selection of Essential Drugs, technical Report Series no.615. Geneva: World Health Organization, 1977.

2. Gama H. Drug Utilization Studies. Arq Med 2008;22:69-74.

3. Salman MT, Khan FA, Rahman SZ, Makhdoom M. Drug Prescribing Pattern in Dental Teaching Hospital. JK Science 2009;11:107.

4. Introduction to drug utilization research. World Health Organization 2003. Available at http://www.whocc.no/filearchive/publications/drug_ utilization_research.pdf. Accessed 19 January 2012.

5. de Vries TPGM, Henning RH, Hogerzeil HV, Fresle DA. Guide to Good Prescribing, A Practical Manual. Geneva: World Health Organization Action Programme on Essential Drugs; 1994. WHO/DAP/94.11. Available at http://whqlibdoc.who.int/hq/1994/WHO_DAP_94.1 1.pdf. Accessed 19 January 2012.

6. World Health Organization. Drug and therapeutics committee: a practical guide. Geneva: World Health Organization; 2003.

doi: 10.5455/2319-2003.ijbcp20130113

Cite this article as: Kulkarni MD, Baig MS, Hussaini SA, Doifode SM. Drug utilization pattern in OPD of government dental college and hospital, Aurangabad. Int J Basic Clin Pharmacol 2013;2:69-70. 